\title{
Article \\ Perinatal Acetaminophen Exposure and Childhood Attention-Deficit/Hyperactivity Disorder (ADHD): Exploring the Role of Umbilical Cord Plasma Metabolites in Oxidative Stress Pathways
}

\author{
Neha S. Anand 1, Ramkripa Raghavan ${ }^{2}$, Guoying Wang ${ }^{2}$, Xiumei Hong ${ }^{2}$, Romuladus E. Azuine ${ }^{3}$, \\ Colleen Pearson ${ }^{4}$, Barry Zuckerman ${ }^{4}$, Hehuang Xie ${ }^{5}$ and Xiaobin Wang ${ }^{1,2, *(D)}$ \\ 1 Department of Pediatrics, Johns Hopkins University School of Medicine, Baltimore, MD 21205, USA; \\ nanand7@jhmi.edu \\ 2 Center on Early Life Origins of Disease, Department of Population, Family and Reproductive Health, \\ Johns Hopkins University Bloomberg School of Public Health, Baltimore, MD 21205, USA; \\ ramkripa@gmail.com (R.R.); gwang24@jhu.edu (G.W.); xhong3@jhu.edu (X.H.) \\ 3 Office of the Director, National Institutes of Health, Bethesda, MD 20892, USA; romuladus.azuine@nih.gov \\ 4 Department of Pediatrics, Boston University School of Medicine and Boston Medical Center, Boston, \\ MA 02118, USA; colleen.pearson@bmc.org (C.P.); barry.zuckerman@bmc.org (B.Z.) \\ check for \\ updates \\ 5 Department of Biomedical Sciences \& Pathobiology, Fralin Life Sciences Institute at Virginia Technology, \\ Blacksburg, VA 24061, USA; davidxie@vt.edu \\ * Correspondence: xwang82@jhu.edu; Tel.: +1-410-955-5824
}

Citation: Anand, N.S.; Raghavan, R.; Wang, G.; Hong, X.; Azuine, R.E.; Pearson, C.; Zuckerman, B.; Xie, H.; Wang, X. Perinatal Acetaminophen Exposure and Childhood Attention-Deficit/Hyperactivity Disorder (ADHD): Exploring the Role of Umbilical Cord Plasma Metabolites in Oxidative Stress Pathways. Brain Sci. 2021, 11, 1302. https://doi.org/ 10.3390/brainsci11101302

Academic Editor:

María García-Fernández

Received: 25 August 2021

Accepted: 29 September 2021

Published: 30 September 2021

Publisher's Note: MDPI stays neutral with regard to jurisdictional claims in published maps and institutional affiliations.

Copyright: () 2021 by the authors. Licensee MDPI, Basel, Switzerland. This article is an open access article distributed under the terms and conditions of the Creative Commons Attribution (CC BY) license (https:// creativecommons.org/licenses/by/ $4.0 /)$.

\begin{abstract}
Oxidative stress mechanisms may explain associations between perinatal acetaminophen exposure and childhood attention-deficit hyperactivity disorder (ADHD). We investigated whether the changes in umbilical cord plasma amino acids needed to synthesize the antioxidant glutathione and in the oxidative stress biomarker 8-hydroxy-deoxyguanosine may explain the association between cord plasma acetaminophen and ADHD in the Boston Birth Cohort (BBC). Mother-child dyads were followed at the Boston Medical Center between 1998 and 2018. Cord plasma analytes were measured from archived samples collected at birth. Physician diagnoses of childhood ADHD were obtained from medical records. The final sample consisted of 568 participants (child mean age [SD]: 9.3 [3.5] years, 315 (52.8\%) male, 248 (43.7\%) ADHD, 320 (56.3\%) neurotypical development). Cord unmetabolized acetaminophen was positively correlated with methionine $(\mathrm{R}=0.33$, $p<0.001)$, serine $(R=0.30, p<0.001)$, glycine $(R=0.34, p<0.001)$, and glutamate $(R=0.16, p<0.001)$. Children with cord acetaminophen levels $>50$ th percentile appeared to have higher risk of ADHD for each increase in cord 8-hydroxy-deoxyguanosine level. Adjusting for covariates, increasing cord methionine, glycine, serine, and 8-hydroxy-deoxyguanosine were associated with significantly higher odds for childhood ADHD. Cord methionine statistically mediated $22.1 \%$ (natural indirect effect $\log \mathrm{OR}=0.167, \mathrm{SE}=0.071, p=0.019$ ) and glycine mediated $22.0 \%$ (natural indirect effect lo$\mathrm{gOR}=0.166, \mathrm{SE}=0.078, p=0.032$ ) of the association between cord acetaminophen $>50$ th percentile with ADHD. Our findings provide some clues, but additional investigation into oxidative stress pathways and the association of acetaminophen exposure and childhood ADHD is warranted.
\end{abstract}

Keywords: ADHD; cord blood; acetaminophen; glutathione; oxidative stress; neurodevelopment

\section{Introduction}

Acetaminophen is the most-commonly used medication during pregnancy for pain and fever [1,2]. Two large European cohort studies, the Norwegian Mother and Child Cohort and the Danish Birth Cohort study, were the first to link maternal report of acetaminophen use during pregnancy with adverse offspring neurodevelopmental outcomes, including attention-deficit hyperactivity disorder (ADHD) [3,4]. Subsequently, several 
studies in Europe, Asia, and the United States have associated perinatal acetaminophen exposure with increased risk of childhood neurodevelopmental disorders [5-18]. Recent meta-analyses of observational studies have also found significant pooled risks for childhood ADHD and hyperactivity symptoms associated with perinatal acetaminophen exposure [19-22].

Although several studies have documented associations between perinatal acetaminophen exposure and the risk of childhood ADHD, possible mechanisms to explain acetaminophen exposure and childhood neurodevelopmental outcomes have not been exhaustively investigated [23]. Gervin et al. found differences in DNA methylation in cord blood samples between children with ADHD versus controls, which were associated with prenatal exposure to acetaminophen for more than 20 days. These differences were found in genes linked to ADHD, neural development, neurotransmission, and pathways involving oxidative stress and the olfactory sensory system. Baker et al. identified altered frontoparietal-sensorimotor brain cortex connectivity as a mediator of the association between acetaminophen exposure in meconium samples and childhood measures of hyperactivity. Animal studies have suggested that acetaminophen may impact fetal development through neuro- and endocrine disruption and through pathways of oxidative stress and inflammation [1,24-26]. However, to date, there have been no studies in humans of biomarkers of metabolic pathways hypothesized to explain the association.

Elucidating the potential mechanism that may explain adverse childhood outcomes associated with acetaminophen exposure, such as ADHD, is of clinical and public health significance $[1,2,23,27]$. In this study, we leverage unique data from a 20 -year longitudinal Boston Birth Cohort (BBC) to investigate the mechanisms that potentially explain the link between acetaminophen and developmental disorders, focusing on oxidative stress pathways. Recent analysis of the BBC, a prospective U.S. birth cohort, found a robust positive association between umbilical cord biomarkers of acetaminophen and childhood diagnosis of ADHD, even with multiple sensitivity analyses [6]. By using umbilical cord data as biomarkers, that study overcame limitations of previous studies that measured prenatal acetaminophen exposure by maternal self-report of acetaminophen use [6].

In the same cord samples from this study of the BBC, several analytes were measured as part of a metabolomic study. We aimed to analyze relationships of cord plasma analytes in these samples that may signal oxidative stress with cord plasma acetaminophen and childhood ADHD. Glutathione, the antioxidant that detoxifies the acetaminophen metabolite N-acetyl-p-benzoquinone imine (NAPQI) [28], was not directly available in the BBC dataset. Thus, we sought to analyze whether four cord plasma amino acids that are necessary for glutathione synthesis [29] (methionine, serine, glycine, and glutamate (Figure 1A)) were associated with cord acetaminophen and risk of childhood ADHD. We hypothesized that cord plasma methionine, serine, glycine, and glutamate would be depleted for children with higher cord plasma acetaminophen exposure due to greater demand and need for glutathione to detoxify acetaminophen. We further hypothesized that the depletion of cord amino acids may explain the association between acetaminophen exposure and childhood risk of ADHD, as these amino acids have roles in other pathways that may be affected, such as epigenetic mechanisms and neurotransmission. Secondly, we aimed to analyze whether cord plasma 8-hydroxy-deoyguanosine, a known biomarker of oxidative damage to DNA, was associated with acetaminophen exposure and ADHD risk [30,31]. 8-Hydroxy-deoxyguanosine is a product of cellular oxidative stress, which can occur when NAPQI causes mitochondrial damage that subsequently leads to the release of reactive oxygen species (Figure 1B) [32]. We hypothesized that for children with higher cord acetaminophen levels, higher 8-hydroxy-deoxyguanosine levels would be associated with ADHD risk. 


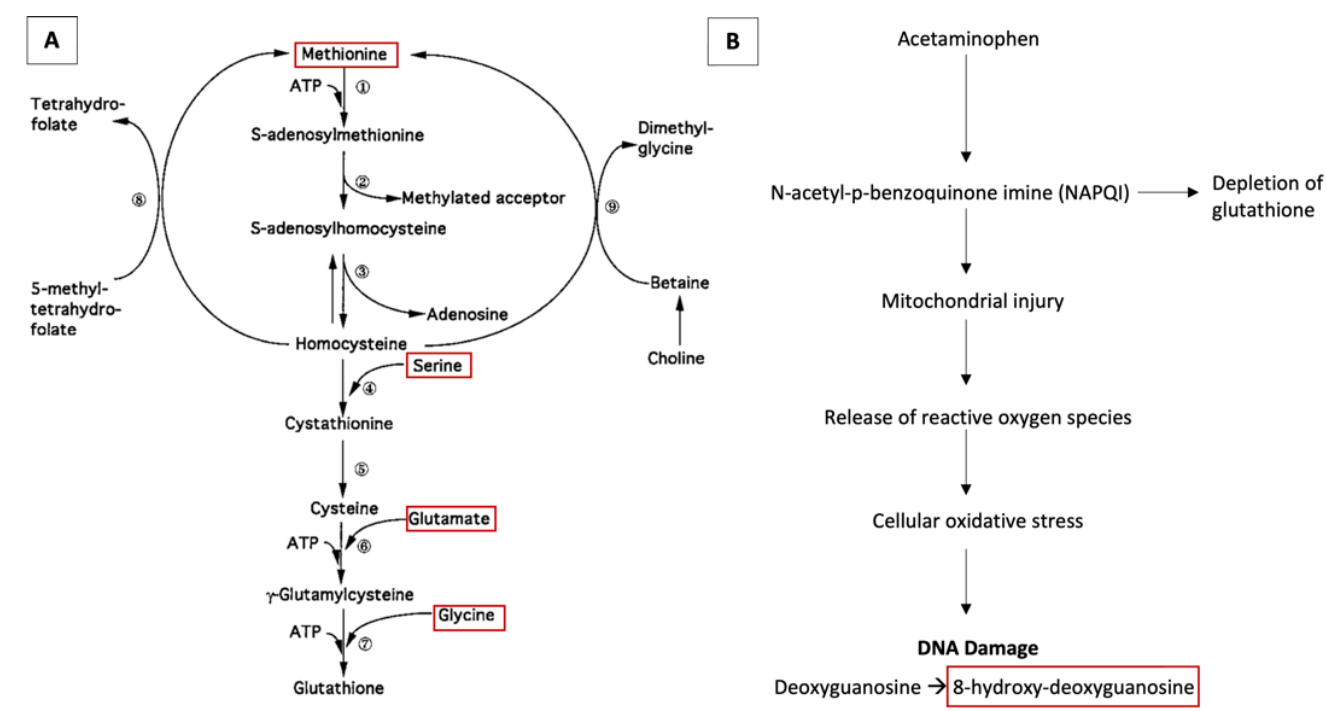

Figure 1. Pathways for synthesis of antioxidant glutathione (A) ${ }^{a}$ and acetaminophen toxicity leading

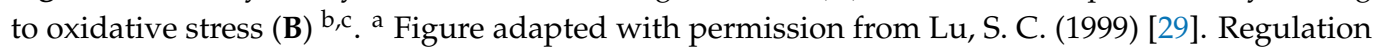
of hepatic glutathione synthesis: current concepts and controversies. FASEB J, 13(10), 1169-1183. b Figure based on Scheme 1 from C. L. Powell et al. [32], "Phenotypic anchoring of acetaminopheninduced oxidative stress with gene expression profiles in rat liver," (in eng), Toxicol Sci, vol. 93, no. 1, pp. 213-22, Sep 2006, doi:10.1093/toxsci/kfl030. ' Selected analytes for study boxed in red.

\section{Materials and Methods}

\subsection{Study Design}

Data came from the Boston Birth Cohort (BBC), which is a prospective birth cohort study of 3165 mother-child pairs followed at the Boston Medical Center (BMC) from 1998 to 2018. Mother-child pairs were enrolled within 24 to $72 \mathrm{~h}$ of the child's birth after written informed consent by the mother. Informed consent was obtained from all subjects involved in the study. Exclusion criteria included multiple gestation pregnancies, in vitro fertilization pregnancies, maternal trauma-induced deliveries, and infants born with major birth defects or chromosomal abnormalities. The BBC is a preterm-enriched cohort. For every preterm (born $<37$ weeks of gestation) or low birthweight infant (born $<2500 \mathrm{~g}$ ), about two term and normal weight infants were enrolled [33]. Children that continued primary pediatric or specialty care at BMC beginning at 6 months of age were invited for post-natal follow-up until the age of 21. The consent of children, written or verbal, was also obtained depending on their age. The initial and post-natal follow-up protocols were approved by the Institutional Review Boards of the Johns Hopkins Bloomberg School of Public Health and the BMC. All data for analyses were de-identified and accessed only by authorized investigators. The full details of the BBC have been previously published [34,35].

\subsection{Independent Variable: Childhood ADHD}

Childhood neurodevelopmental diagnoses were categorized based on clinician documentation of primary and secondary diagnoses in electronic medical records up to June 2018. The ADHD-only category included children with only ADHD-related codes (ICD-9 codes 314.0-314.9; ICD-10 codes F90.0-F90.9) and excluded children with autism spectrum disorder (ASD) diagnoses (ICD-9 codes 299.0-299.91; ICD-10 codes F84.0-F84.9) or other mental, behavioral, and neurodevelopmental disorders (ICD-9 codes 290-319; ICD-10 codes F01-F99). The neurotypical development category included children without ADHD, ASD, or other developmental disability diagnoses.

\subsection{Dependent Variables: Umbilical Cord and Maternal Plasma Analytes}

Umbilical cord blood samples were collected at birth, and maternal non-fasting plasma samples were obtained at the time of enrollment (within 24-72 h after delivery). Both 
maternal and cord blood samples were processed and fractionated into cells and plasma shortly after collection by the field team at the BMC. Quantitative profiling of analytes, including unmetabolized acetaminophen, methionine, serine, glycine, glutamate, and 8-hydroxy-deoxyguanosine from cord and maternal plasma samples was performed at the Harvard-MIT Broad Institute Metabolite Profiling Laboratory using liquid chromatographytandem mass spectrometry. Due to the skewed distribution of most cord analytes, inverse normal transformation was used to render the distribution approximately normal. Details on laboratory methods, quality control, and data processing have been previously described [6,36].

\subsection{Maternal and Child Covariates}

We included covariates drawing upon previously published analyses of the BBC [6]. These included maternal age at delivery (in years); parity (nulliparous vs. multiparous); maternal race/ethnicity (Black, White, Hispanic, or Other); maternal education level (below college degree vs. above college degree); maternal body mass index (BMI); stress during pregnancy (mild, average, severe); smoking during pregnancy (never, quit, or continuous); alcohol use before or during pregnancy; marital status (not married vs. married); child sex, delivery type (cesarean vs. vaginal); preterm birth ( $<37$ weeks); low birthweight $(<2500 \mathrm{~g})$; stress during pregnancy (mild, average, or severe); and maternal fever during pregnancy (yes vs. no).

\subsection{Statistical Analyses}

Our statistical analyses followed five steps. First, unmetabolized cord acetaminophen was cut at 0.0301 , the 50th percentile, for analyses based on its graphical association with ADHD risk (Figure S1). Then, maternal and child characteristics for children with acetaminophen levels $\leq 50$ th percentile and vs. $>50$ th percentile were compared with analysis of variance tests (ANOVA) for continuous characteristics and Pearson's chi-squared test for categorical characteristics. Simple imputation was used for missing sociodemographic characteristics. The median was imputed for continuous variables, and the most frequent value was imputed for categorical variables.

Second, we calculated Pearson correlations between selected cord analytes, and unmetabolized acetaminophen as well as 8-hydroxy-deoxyguanosine were calculated. Third, we plotted the associations between childhood ADHD risk and cord unmetabolized acetaminophen stratified by above and below the 50th percentile of 8-hydroxydeoxyguanosine. Similarly, the associations between childhood ADHD risk and cord 8-hydroxy-deoxyguanosine stratified by above and below the 50th percentile of unmetabolized acetaminophen were plotted for the total sample as well as for males and females separately. In supplementary analysis, we compared the odds of childhood ADHD of the following four groups for the total sample, males, and females: cord acetaminophen $\leq 50$ th percentile and 8-hydroxy-deoxyguanosine $\leq 50$ th percentile (reference), cord acetaminophen $\leq 50$ th percentile and 8-hydroxy-deoxyguanosine $>50$ th percentile, cord acetaminophen $>50$ th percentile and 8-hydroxy-deoxyguanosine $\leq 50$ th percentile, and cord acetaminophen $>50$ th percentile and 8-hydroxy-deoxyguanosine $>50$ th percentile.

Fourth, we used unadjusted and adjusted logistic regressions to examine the associations between cord acetaminophen and selected cord analytes with childhood diagnosis of ADHD with neurotypical development as the reference group. Given the positive association between unmetabolized acetaminophen and many of the selected analytes, we aimed to assess whether adjusting for analytes in regressions may attenuate the odds of ADHD for cord acetaminophen levels $>50$ th percentile, which would signal possible statistical mediation. In supplementary analysis, we conducted the same regressions for maternal plasma analytes in addition to determining the Pearson correlations for maternal and selected cord plasma analytes.

Lastly, we used the VanderWeele-Vansteelandt approach to estimate the natural indirect effect of selected cord analytes for the association between cord acetaminophen 
and ADHD with the 'medflex' package in R [37]. Sensitivity analyses for the mediation analyses were performed for the data that excluded preterm births, maternal alcohol use, maternal smoking during pregnancy, and maternal fever. For all analyses, children who were siblings with another participant in the $\mathrm{BBC}$ were excluded to maintain independence of subjects in analyses.

\section{Results}

\subsection{Maternal and Child Characteristics}

The source population of 3165 mother-child dyads included 433 (13.7\%) participants with a childhood diagnosis of ADHD only and $1444(45.6 \%)$ with neurotypical development. Of these, 965 participants had cord plasma analyte data when excluding siblings, of which $248(25.7 \%)$ had childhood ADHD and $320(33.2 \%)$ had neurotypical development. Table 1 compares maternal and child characteristics for the total analytic sample of 568 dyads between those with cord unmetabolized acetaminophen levels $\leq 50$ th percentile vs. $>50$ th percentile. Children with cord acetaminophen $>50$ th percentile were significantly more likely to have childhood ADHD diagnosis, mothers who smoked during pregnancy, and low birthweight. Further, cord methionine, serine, glycine, and glutamate levels were higher for those with cord acetaminophen levels $>50$ th percentile.

Table 1. Maternal and child characteristics by cord plasma acetaminophen $\leq 50$ th percentile vs. $>50$ th $_{\text {percentile }}{ }^{\text {a }}$.

\begin{tabular}{|c|c|c|c|c|c|}
\hline Characteristics & Total & $\begin{array}{l}\text { Cord } \\
\text { Acetaminophen } \\
\leq 50 \text { th Percentile }\end{array}$ & $\begin{array}{c}\text { Cord } \\
\text { Acetaminophen } \\
\text { >50th Percentile }\end{array}$ & $p$-Value ${ }^{b}$ & $\%$ Missing $^{c}$ \\
\hline$n$ & 568 & 284 & 284 & & \\
\hline Childhood ADHD diagnosis, $n(\%)$ & 248 & $97(34.2 \%)$ & $151(53.2 \%)$ & $<0.001 *$ & \\
\hline Maternal age (years), mean (SD) & $28.0(6.6)$ & $28.0(6.4)$ & $28.0(6.8)$ & 0.973 & \\
\hline Nulliparous, $n(\%)$ & 243 & $112(39.4 \%)$ & $131(46.1 \%)$ & 0.107 & \\
\hline Maternal Race or ethnicity, $n(\%)$ & & & & 0.111 & \\
\hline Black & 276 & $190(66.9 \%)$ & $186(65.5 \%)$ & & \\
\hline White & 32 & $12(4.2 \%)$ & $20(7.0 \%)$ & & \\
\hline Hispanic & 118 & $55(19.4 \%)$ & $63(22.2 \%)$ & & \\
\hline Other & 42 & $27(9.5 \%)$ & $15(5.3 \%)$ & & \\
\hline Maternal Education, $n(\%)$ & & & & 0.855 & $0.53 \%$ \\
\hline Below College Degree & 396 & $199(70.1 \%)$ & $197(69.4 \%)$ & & \\
\hline College Degree or Above & 172 & $85(29.9 \%)$ & $97(30.6 \%)$ & & \\
\hline Maternal BMI $\left(\mathrm{kg} / \mathrm{m}^{2}\right)$, mean $(S D)$ & $26.4(6.1)$ & $26.0(6.2)$ & $26.7(5.9)$ & 0.170 & $5.46 \%$ \\
\hline Maternal smoking, $n(\%)$ & & & & 0.005 * & $1.23 \%$ \\
\hline Never & 484 & $255(89.8 \%)$ & $229(80.6 \%)$ & & \\
\hline Quit & 33 & $14(4.9 \%)$ & $19(6.7 \%)$ & & \\
\hline Continuous & 51 & $15(5.3 \%)$ & $36(12.7 \%)$ & & \\
\hline $\begin{array}{l}\text { Maternal alcohol use before or during } \\
\text { pregnancy, } n(\%)\end{array}$ & & & & 0.107 & $4.05 \%$ \\
\hline No & 535 & $272(85.8 \%)$ & $263(92.6 \%)$ & & \\
\hline Yes & 33 & $12(4.2 \%)$ & $21(7.4 \%)$ & & \\
\hline Marital Status, $n(\%)$ & & & & 0.181 & $0.88 \%$ \\
\hline Not Married & 381 & $183(64.4 \%)$ & $198(69.7 \%)$ & & \\
\hline Married & 187 & $101(35.6 \%)$ & $86(30.3 \%)$ & & \\
\hline Child age in years by last visit, mean (SD) & $9.3(3.5)$ & $9.6(3.5)$ & $9.1(3.4)$ & 0.129 & \\
\hline Child Sex, $n(\%)$ & & & & 0.205 & \\
\hline Male & 315 & $150(52.8 \%)$ & $165(58.1 \%)$ & & \\
\hline Female & 253 & $134(47.2 \%)$ & $119(41.9 \%)$ & & \\
\hline Delivery type, $n(\%)$ & & & & 0.857 & $0.53 \%$ \\
\hline Cesarean & 180 & $91(32.0 \%)$ & $89(31.3 \%)$ & & \\
\hline Vaginal & 388 & $193(68.0 \%)$ & $195(68.7 \%)$ & & \\
\hline Preterm, $n(\%)$ & & & & 0.051 & \\
\hline No & 490 & $253(89.1 \%)$ & $237(83.5 \%)$ & & \\
\hline Yes & 78 & $31(10.9 \%)$ & $47(16.5 \%)$ & & \\
\hline Low Birthweight, $n(\%)$ & & & & $0.002^{c, *}$ & $0.18 \%$ \\
\hline No & 482 & $254(89.4 \%)$ & $228(80.3 \%)$ & & \\
\hline Yes & 86 & $30(10.6 \%)$ & $56(19.7 \%)$ & & \\
\hline
\end{tabular}


Table 1. Cont.

\begin{tabular}{|c|c|c|c|c|c|}
\hline Characteristics & Total & $\begin{array}{l}\text { Cord } \\
\text { Acetaminophen } \\
\leq 50 \text { th Percentile }\end{array}$ & $\begin{array}{c}\text { Cord } \\
\text { Acetaminophen } \\
>\text { >50th Percentile }\end{array}$ & $p$-Value ${ }^{\mathrm{b}}$ & $\%$ Missing ${ }^{c}$ \\
\hline Stress During Pregnancy, $n(\%)$ & & & & 0.444 & $0.88 \%$ \\
\hline Mild & 219 & $116(40.8 \%)$ & $103(36.3 \%)$ & & \\
\hline Average & 246 & $121(42.6 \%)$ & $125(44.0 \%)$ & & \\
\hline Severe & 103 & $47(16.5 \%)$ & $56(19.7 \%)$ & & \\
\hline Maternal Fever During Pregnancy, $n(\%)$ & & & & 0.844 & $5.11 \%$ \\
\hline No & 541 & $271(95.4 \%)$ & $270(95.1 \%)$ & & \\
\hline Yes & 27 & $13(4.6 \%)$ & $14(4.9 \%)$ & & \\
\hline Cord methionine $^{\text {a }}$ (mean, SD) & $0.04(0.99)$ & $-0.28(0.93)$ & $0.37(0.94)$ & $<0.001 *$ & \\
\hline Cord serine $^{\text {a }}($ mean,$S D)$ & $0.01(0.98)$ & $-0.31(0.90)$ & $0.33(0.96)$ & $<0.001 *$ & \\
\hline Cord glycine $^{\text {a }}$ (mean, $S D$ ) & $0.03(1.01)$ & $-0.33(0.91)$ & $0.39(0.98)$ & $<0.001 *$ & \\
\hline Cord glutamate a (mean, $S D)$ & $0.06(1.00)$ & $-0.13(1.01)$ & $0.24(0.95)$ & $<0.001 *$ & \\
\hline $\begin{array}{l}\text { Cord 8-hydroxy-deoxyguanosine }{ }^{\text {a }} \\
(\text { mean }, S D)\end{array}$ & $0.08(0.95)$ & $0.06(0.93)$ & $0.10(0.98)$ & 0.604 & \\
\hline
\end{tabular}

${ }^{a}$ Inverse normal transformed intensities ${ }^{b} p$-values calculated using analysis of variance tests (continuous variables) or Pearson chi-sq tests (categorical variables) ${ }^{\mathrm{c}}$ Missing characteristics imputed with the median for continuous variables or the most frequent value for categorical variables $* p<0.05$.

\subsection{Correlations of Cord Plasma Methionine, Serine, Glycine, and Glutamate with Cord Plasma Unmetabolized Acetaminophen and 8-Hydroxy-Deoxyguanosine}

Figure 2A-D display the correlations between cord unmetabolized acetaminophen and the selected cord analytes. Cord acetaminophen was positively correlated with methionine $(\mathrm{R}=0.33, p<0.001)$, serine $(\mathrm{R}=0.30, p<0.001)$, glycine $(\mathrm{R}=0.34, p<0.001)$, and glutamate $(\mathrm{R}=0.16, p<0.001)$. Figure $3 \mathrm{~A}-\mathrm{D}$ displays positive correlations between cord 8-hydroxydeoxyguanosine and cord methionine $(\mathrm{R}=0.33, p<0.001)$, serine $(\mathrm{R}=0.33, p<0.001)$, glycine $(R=0.25, p<0.001)$, and glutamate $(R=0.21, p<0.001)$.
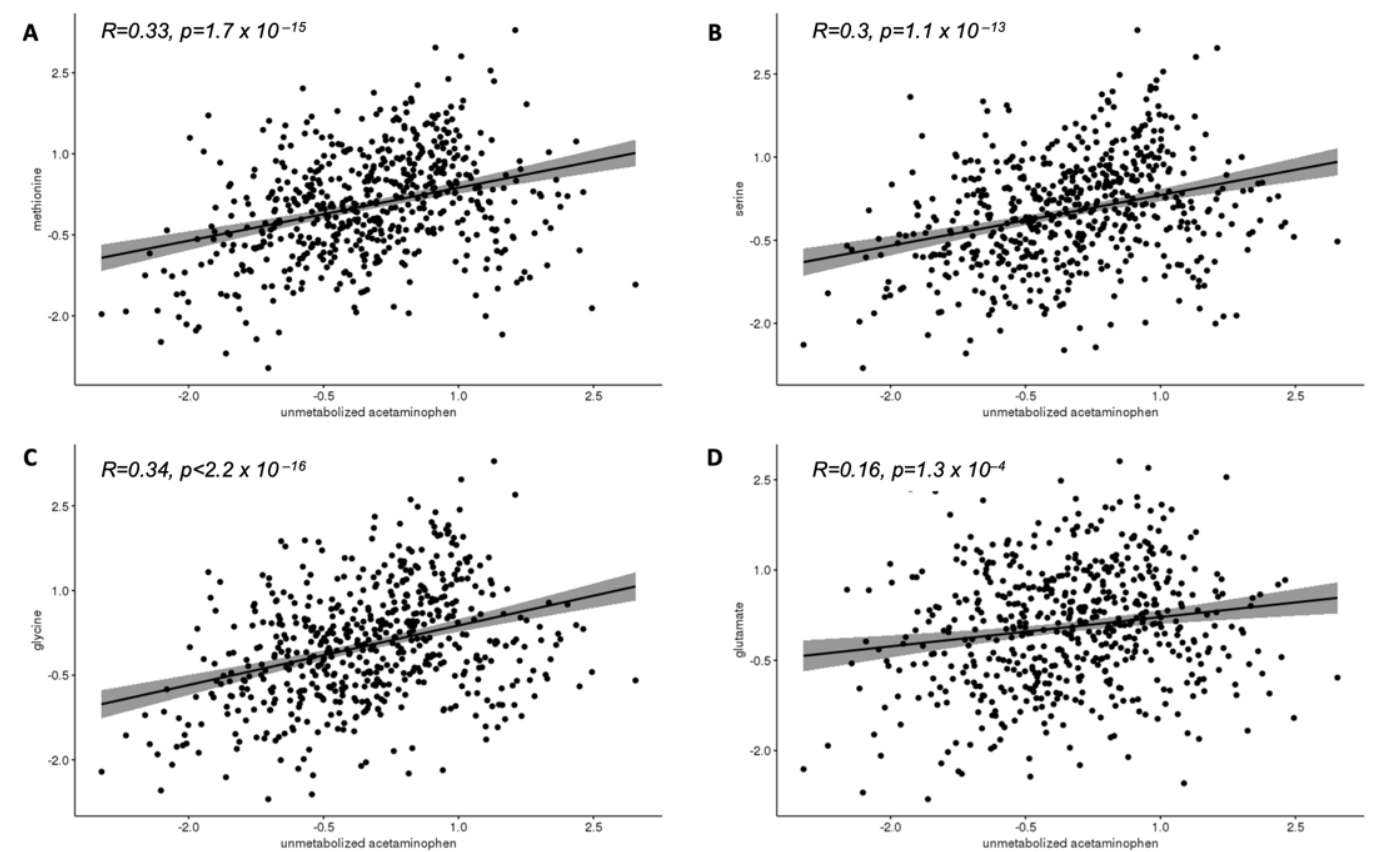

Figure 2. Associations of cord plasma unmetabolized acetaminophen ${ }^{\text {a }}$ with cord plasma methionine (A), serine (B), glycine (C), and glutamate (D) ${ }^{\text {a }}{ }^{\text {a }}$ Inverse normal transformed intensities. 

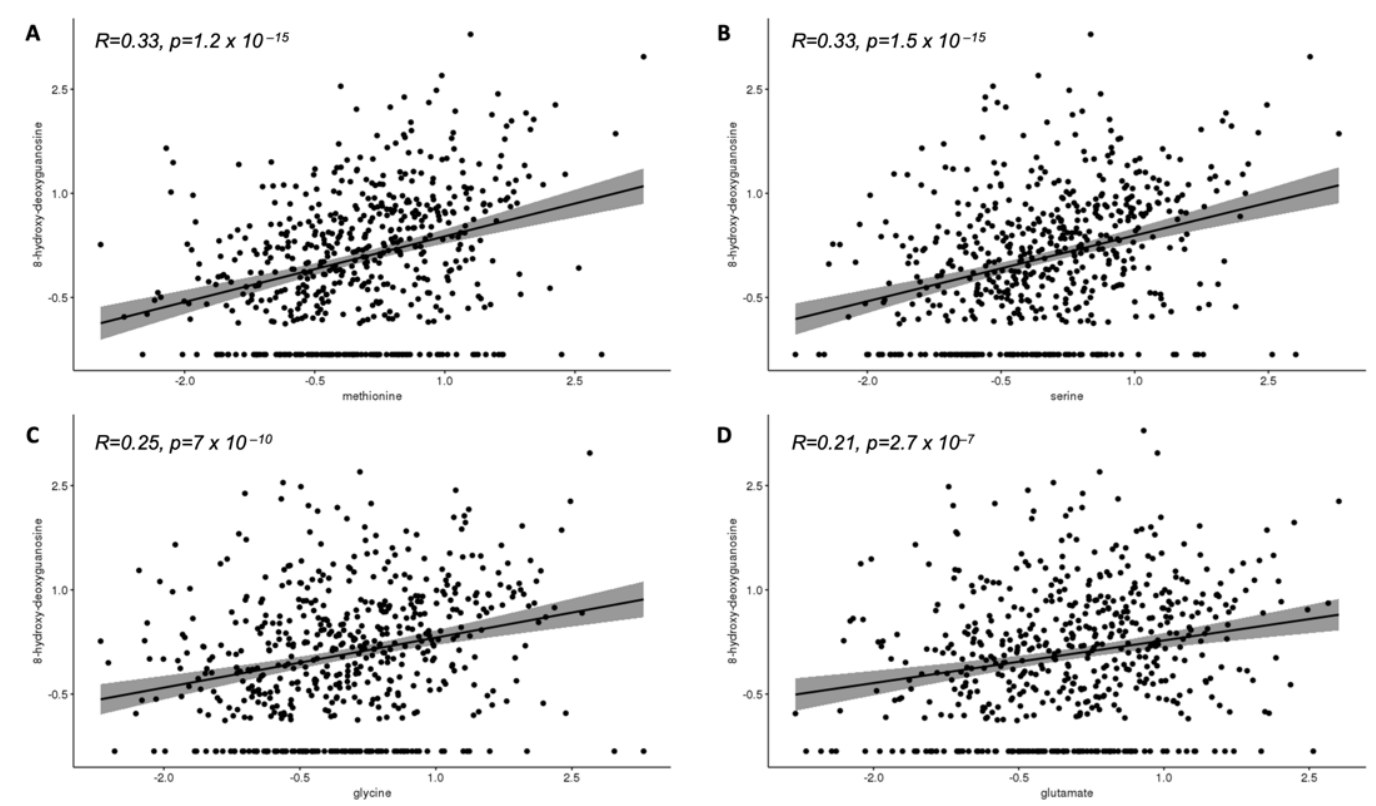

Figure 3. Association of cord plasma methionine (A), serine (B), glycine (C), and glutamate (D) with cord plasma 8-hydroxy-deoxyguanosine ${ }^{\mathrm{a}}$. ${ }^{\mathrm{a}}$ Inverse normal transformed intensities.

3.3. Correlations of Cord Plasma Methionine, Serine, Glycine, and Glutamate with Cord Plasma Unmetabolized Acetaminophen and 8-Hydroxy-Deoxyguanosine

In Figure 4A, children with cord 8-hydroxy-deoxyguanosine levels $>50$ th percentile compared to below appear to have higher risk of ADHD for each increase in acetaminophen level. Further, children with cord acetaminophen levels $>50$ th percentile compared to $\leq 50$ th percentile appear to have a higher risk of ADHD for each increase in 8-hydroxydeoxyguanosine level (Figure 4B). This finding is consistent for both males (Figure 4C) and females (Figure 4D), although females have an overall lower risk of ADHD. Table S1 demonstrates that children with cord acetaminophen $>50$ th percentile had significantly higher odds of ADHD when cord 8-hydroxy-deoxyguanosine levels were $\leq 50$ th percentile (OR: $2.21,95 \%$ CI $(1.37,3.58), p=0.001)$ and even higher odds when 8-hydroxy-deoxyguanosine was $>50$ th percentile (OR: $2.38,95 \%$ CI $(1.49,3.82), p<0.001)$ compared to children with both cord acetaminophen and 8-hydroxy-deoxyguansoine levels $\leq 50$ th percentiles for the total sample. These findings were consistent for males but not females, although the sample size was reduced when stratifying.

\subsection{Logistic Regressions of Odds of ADHD and Cord Plasma Analytes}

Table 2 displays logistic regressions results of childhood ADHD diagnosis with the selected cord analytes, unadjusted and adjusted for covariates. Cord unmetabolized acetaminophen $>50$ th percentile was associated with higher odds of ADHD diagnosis (aOR: $2.10,95 \%$ CI $(1.43,3.11), p<0.001)$. In adjusted regressions, increasing levels of cord methionine (aOR: 1.43, 95\% CI $(1.17,1.77), p=0.001)$, serine (aOR: $1.38,95 \%$ CI $(1.14,1.68)$, $p=0.008)$, glycine (aOR: 1.38, 95\% CI (1.14, 1.68), $p=0.001)$, and 8-hydroxy-deoxyguanosine (aOR: $1.24,95 \%$ CI $(1.01,1.52), p=0.039)$ were associated with higher odds of ADHD as well but not cord glutamate.

When including both cord acetaminophen and cord methionine or glycine in the regression model, the odds ratio for diagnosis of any ADHD for children with cord plasma acetaminophen $>50$ th percentile vs. $\leq 50$ th percentile decreased by $14-15 \%$ (cord acetaminophen $\geq 50$ th percentile only: aOR: $2.10,95 \%$ CI $(1.43,3.11), p<0.001$; with methionine: aOR: $1.79,95 \%$ CI $(1.19,2.71), p=0.005$; with glycine: aOR: $1.80,95 \% \mathrm{CI}$ $(1.19,2.73), p=0.005)$. The increased odds of ADHD for each unit increase of cord methionine or cord glycine also remained significant when included in the model with cord acetaminophen (methionine: aOR: $1.30,95 \%$ CI $(1.05,1.62), p=0.018$; glycine: aOR: 1.26 , 
$95 \%$ CI $(1.02,1.54), p=0.030)$. Cord serine did not have a significant odds ratio when included in the regression with cord acetaminophen $>50$ th percentile, and including cord glutamate or 8-hydroxy-deoxyguanosine did not substantially attenuate the odds ratio for cord acetaminophen. Table $\mathrm{S} 2$ displays the adjusted logistic regression results stratified by males and females. For males, when including cord acetaminophen $\geq 50$ th percentile in the regression, cord methionine, serine, and glycine were no longer significantly associated with higher odds of ADHD. However, for females, these cord analytes remained significant, and cord acetaminophen $\geq 50$ th percentile was not significantly associated with ADHD. Of note, the sample size of children with ADHD was considerably reduced for females (196 neurotypical, 57 ADHD).

A

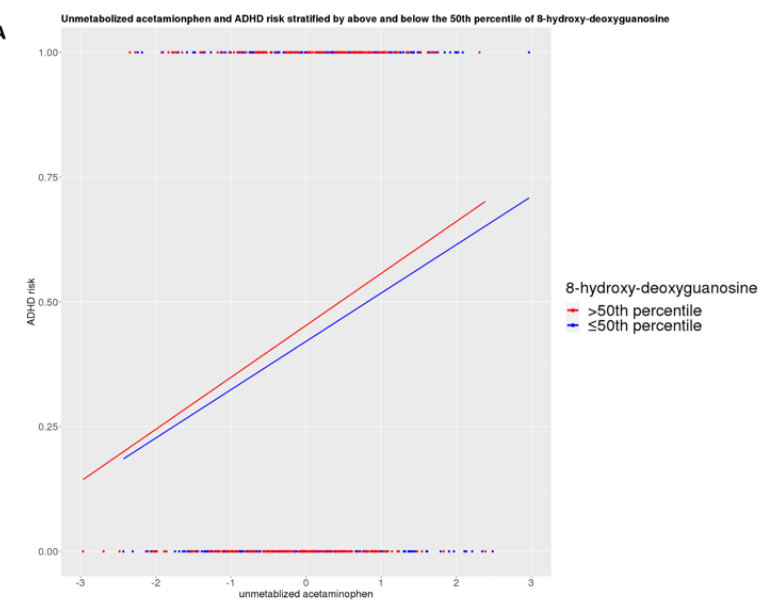

c

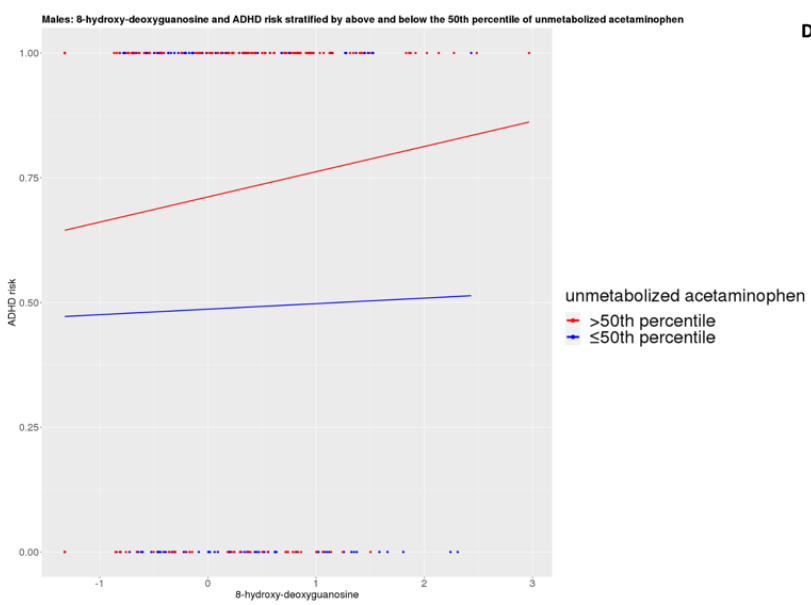

B

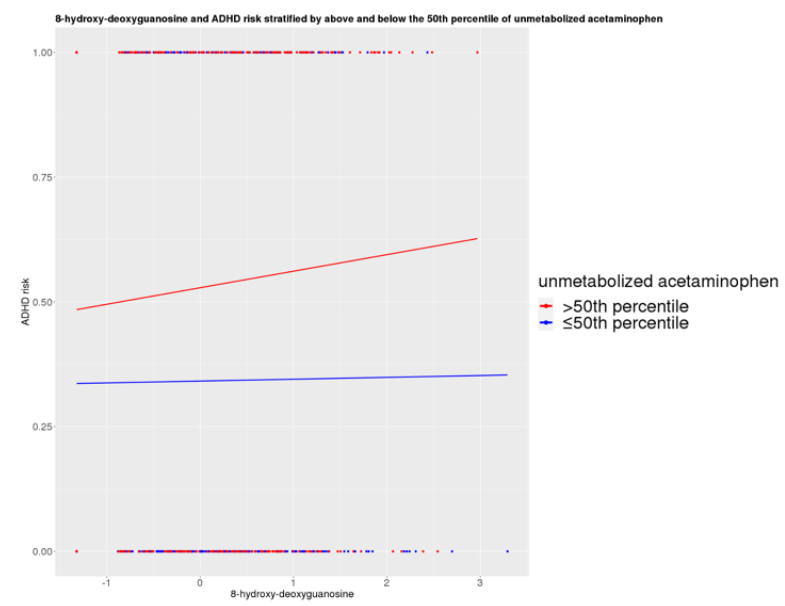

D

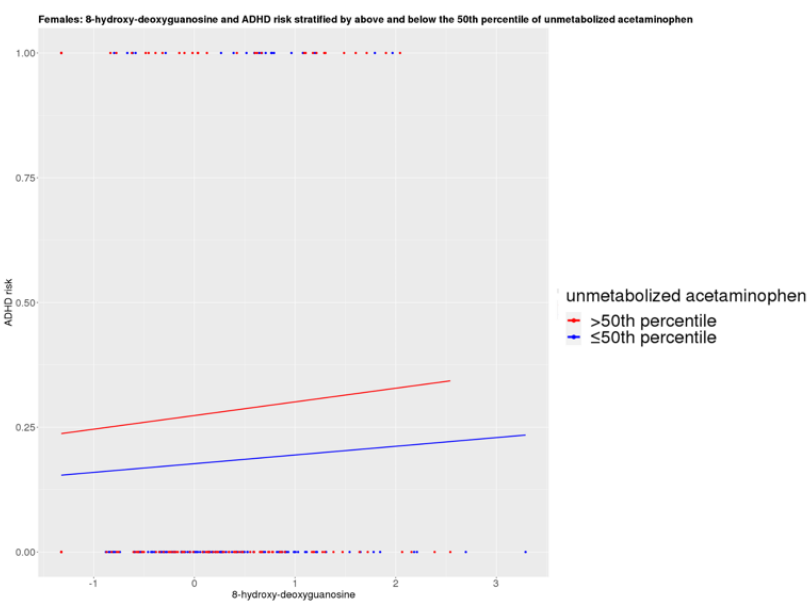

Figure 4. Inter-relationships of cord plasma unmetabolized acetaminophen a, 8-hydroxy-deoxyguanosine ${ }^{a}$, and childhood $\mathrm{ADHD}^{\mathrm{b}}$. (A): Cord unmetabolized acetaminophen and ADHD risk stratified by cord 8-hydroxy-deoxyguanosine above and below 50th percentile. (B): Cord 8-hydroxy-deoxyguanosine and ADHD risk stratified by cord unmetabolized acetaminophen above and below 50th percentile. (C): Males: cord 8-hydroxy-deoxyguanosine and ADHD risk stratified by cord unmetabolized acetaminophen above and below 50th percentile. (D): Females: cord 8-hydroxy-deoxyguanosine and ADHD risk stratified by cord unmetabolized acetaminophen above and below 50th percentile. ${ }^{a}$ Inverse normal transformed intensities. ${ }^{\mathrm{b}}$ Reference group $=$ neurotypical development. 
Table 2. Logistic regressions examining risk of childhood ADHD for cord plasma metabolites ${ }^{\text {a }}$.

\begin{tabular}{|c|c|c|c|c|c|c|c|}
\hline & \multirow[b]{2}{*}{$n$} & \multicolumn{3}{|c|}{ Unadjusted Logistic } & \multicolumn{3}{|c|}{ Adjusted Logistic d } \\
\hline & & $\begin{array}{l}\text { Odds } \\
\text { Ratio }\end{array}$ & $95 \% \mathrm{CI}$ & $p$-Value & $\begin{array}{l}\text { Odds } \\
\text { Ratio }\end{array}$ & $95 \%$ CI & $p$-Value \\
\hline ADHD only ${ }^{a}$ & 568 & & & & & & \\
\hline \multicolumn{8}{|l|}{ regressions for individual metabolites $b$} \\
\hline acetaminophen $>50$ th percentile $\mathrm{e}^{\mathrm{c}}$ & & 2.23 & $(1.59,3.13)$ & $<0.001 *$ & 2.10 & $(1.43,3.11)$ & $<0.001$ * \\
\hline methionine & & 1.34 & $(1.13,1.60)$ & $0.001 *$ & 1.43 & $(1.17,1.77)$ & 0.001 * \\
\hline glycine & & 1.33 & $(1.12,1.57)$ & $0.001 *$ & 1.38 & $(1.14,1.68)$ & 0.001 * \\
\hline serine & & 1.26 & $(1.07,1.50)$ & $0.008 *$ & 1.31 & $(1.07,1.61)$ & 0.008 * \\
\hline glutamate & & 1.23 & $(1.04,1.45)$ & $0.018 *$ & 1.21 & $(0.99,1.47)$ & 0.058 \\
\hline 8-hydroxy-deoxyguanosine & & 1.09 & $(0.92,1.30)$ & 0.328 & 1.24 & $(1.01,1.52)$ & $0.039 *$ \\
\hline \multicolumn{8}{|l|}{$\begin{array}{l}\text { regression with both acetaminophen } \\
\text { and methionine } b\end{array}$} \\
\hline acetaminophen $>50$ th percentile ${ }^{c}$ & & 1.98 & $(1.39,2.84)$ & $<0.001 *$ & 1.79 & $(1.19,2.71)$ & 0.005 * \\
\hline methionine & & 1.20 & $(1.00,1.45)$ & 0.050 & 1.30 & $(1.05,1.62)$ & $0.018^{*}$ \\
\hline \multicolumn{8}{|l|}{$\begin{array}{c}\text { regression with both acetaminophen } \\
\text { and serine }\end{array}$} \\
\hline acetaminophen $>50$ th percentile ${ }^{c}$ & & 2.07 & $(1.45,2.97)$ & $<0.001 *$ & 1.89 & $(1.26,2.87)$ & $0.002 *$ \\
\hline serine & & 1.12 & $(0.93,1.35)$ & 0.217 & 1.18 & $(0.95,1.46)$ & 0.128 \\
\hline \multicolumn{8}{|l|}{$\begin{array}{l}\text { regression with both acetaminophen } \\
\text { and glycine }\end{array}$} \\
\hline acetaminophen $>50$ th percentile $^{c}$ & & 1.99 & $(1.39,2.85)$ & $<0.001 *$ & 1.80 & $(1.19,2.73)$ & $0.005^{*}$ \\
\hline glycine & & 1.18 & $(0.99,1.42)$ & 0.071 & 1.26 & $(1.02,1.54)$ & $0.030 *$ \\
\hline \multicolumn{8}{|l|}{$\begin{array}{l}\text { regression with both acetaminophen } \\
\text { and glutamate }\end{array}$} \\
\hline acetaminophen $>50$ th percentile ${ }^{c}$ & & 2.12 & $(1.50,3.00)$ & $<0.001 *$ & 2.01 & $(1.35,2.99)$ & 0.001 * \\
\hline serine & & 1.15 & $(0.96,1.37)$ & 0.126 & 1.13 & $(0.93,1.39)$ & 0.219 \\
\hline \multicolumn{8}{|l|}{$\begin{array}{l}\text { regression with both acetaminophen } \\
\text { and 8-hydroxy-deoxyguanosine }\end{array}$} \\
\hline acetaminophen $>50$ th percentile ${ }^{c}$ & & 2.22 & $(1.58,3.13)$ & $<0.001 *$ & 2.08 & $(1.41,3.09)$ & $<0.001 *$ \\
\hline 8-hydroxy-deoxyguanosine & & 1.08 & $(0.91,1.29)$ & 0.380 & 1.23 & $(1.00,1.51)$ & $0.051 *$ \\
\hline
\end{tabular}

${ }^{a}$ Reference group = neurotypical development $(\mathrm{N}=320)$; ADHD only $(\mathrm{N}=248)$ : children with only a neurodevelopmental diagnosis of attention-deficit hyperactivity disorder ${ }^{b}$ Inverse normal transformed intensities ${ }^{\mathrm{c}}$ Reference group $=$ cord acetaminophen level $\leq 50$ th percentile ${ }^{\mathrm{d}}$ Adjusted model covariates: maternal age at delivery in years, parity (nulliparous vs. multiparous), maternal race/ethnicity (Black, White, Hispanic, or Other), maternal education level (below college degree vs. above college degree), maternal body mass index (BMI), stress during pregnancy (mild, average, severe), maternal fever during pregnancy (yes, no), smoking during pregnancy (never, quit, or continuous), alcohol use before or during pregnancy, marital status (not married vs. married), child sex, delivery type (cesarean vs. vaginal), preterm birth ( $<37$ weeks), and low birthweight $(<2500 \mathrm{~g}){ }^{*} p<0.05$.

3.5. Cord Plasma Methionine and Glycine as Partial Mediators for the Association between Cord Plasma Unmetabolized Acetaminophen and Childhood ADHD

Given the positive correlation between cord acetaminophen and cord methionine and glycine, significantly higher odds of ADHD with each unit of cord methionine or glycine, and the attenuation of the odds of ADHD for cord acetaminophen levels $>50$ th percentile when adjusting for cord methionine or glycine in the total sample, mediation analysis was pursued. Using the VanderWeele-Vansteelandt approach, increasing cord methionine was estimated to mediate $22.1 \%$ of the association between cord acetaminophen $>50$ th percentile on subsequent childhood ADHD (natural indirect effect log odds ratio: 0.167, SE: $0.071, p=0.019$ ) and increasing cord glycine mediated $22.0 \%$ of the association (natural indirect effect logs odds ratio: 0.166, SE: 0.078, $p=0.032$ ), (Table S3). Modeling cord acetaminophen as a continuous variable in the mediation yielded similar results for both increasing cord methionine and cord glycine.

In sensitivity analyses (Table S4), cord methionine significantly or borderline significantly partially mediated the association between cord acetaminophen $>50$ th percentile and 
childhood ADHD diagnosis when excluding preterm births $(23.9 \%, p=0.049)$, maternal alcohol use $(18.8 \%, p=0.056)$, maternal smoking $(29.0 \%, p=0.013 \%)$, or maternal fever $(30.3 \%, p=0.007)$. Cord glycine significantly mediated the association when excluding maternal smoking $(30.1 \%, p=0.025)$ and maternal fever $(29.8 \%, p=0.010)$ but not when excluding preterm births $(19.6 \%, p=0.149)$ or maternal alcohol use $(18.8 \%, p=0.071)$.

\subsection{Correlations of Cord and Maternal Plasma Methionine and Glycine and Associations of Maternal Plasma Methionine and Glycine with Childhood ADHD}

Lastly, maternal plasma methionine and glycine levels were compared to cord methionine and glycine levels respectively for 453 mother-child dyads with available maternal analyte data. While maternal methionine and cord methionine were significantly correlated for children with neurotypical development $(R=0.156, p=0.008)$, they were not correlated for children with diagnoses of ADHD only $(\mathrm{R}=-0.074, p=0.349)$. Further maternal methionine was not significantly associated with increased odds for ADHD diagnosis (aOR: $1.02,95 \%$ CI $(0.80,1.29), p=0.894)$, (Table S5). Maternal glycine was correlated with cord glycine for both neurotypical $(\mathrm{R}=0.282, p<0.001)$ and ADHD only groups $(\mathrm{R}=0.275$, $p<0.001)$. However, maternal glycine was also not significantly associated with increased odds for ADHD diagnosis (aOR: 0.92, 95\% CI $(0.72,1.17), p=0.490)$, (Table S2).

\section{Discussion}

\subsection{Main Findings and Interpretation}

In this subset of the prospective Boston Birth Cohort study, we hypothesized that cord plasma amino acids involved in the synthesis of the antioxidant glutathione (Figure 1A) would be decreased for children with higher cord plasma acetaminophen levels and may explain the association between acetaminophen exposure and childhood risk of ADHD. We further hypothesized that 8-hydroxy-deoxyguanosine, a biomarker of oxidative stress (Figure 1B), would be associated with ADHD risk for children with higher cord acetaminophen levels. We found that increased levels of umbilical cord plasma methionine, serine, glycine, and glutamate, which are precursors of glutathione, were correlated with cord unmetabolized acetaminophen and the oxidative stress biomarker 8-hydroxydeoxyguanosine. For children with cord acetaminophen $>50$ th percentile compared to $\leq 50$ th percentile, increasing 8-hydroxy-deoxyguanosine appeared to be associated with greater risk of childhood ADHD. In regressions adjusting for covariates, increasing levels of cord methionine, serine, glycine, and 8-hydroxy-deoxyguanosine, but not glutamate, were found to be associated with higher odds of childhood ADHD compared to neurotypical development. Further, both increasing cord methionine and glycine partially statistically mediated the association between cord acetaminophen levels $>50$ th percentile and childhood ADHD diagnosis. These mediation findings were significant or borderline significant when analyzing subgroups that excluded known risk factors for ADHD such as preterm birth, maternal smoking, and maternal alcohol use [38,39].

These findings are in opposition to our original hypothesis that lower levels of amino acids involved in the synthesis of glutathione may explain the association between cord acetaminophen and ADHD risk. However, elevated levels of methionine, serine, glycine, and glutathione were significantly correlated with the oxidative stress biomarker 8-hydroxydeoxyguanosine. This may suggest that potential disruption of the homeostasis of glutathione synthesis by acetaminophen is associated with increased oxidative stress. In a study of rats, subtoxic and toxic doses of acetaminophen led to a significant increase in 8-hydroxy-deoxyguanosine and a decrease in glutathione [32]. Indeed, the significant association of higher levels of 8-hydroxy-deoxyguanosine with higher odds of ADHD in this study is consistent with our original hypothesis of the oxidative stress biomarker being associated with childhood ADHD risk. Though oxidative stress is a hypothesized mechanism for the development of ADHD, few studies have looked at the association of 8-hydroxy-deoxyguanosine with childhood ADHD. One case-control study found higher levels of urinary 8-hydroxy-deoxyguanosine in children 6 to 12 years old with ADHD 
compared to those without ADHD [40]. However, another study has reported lower levels of 8-hydroxy-deoxyguanosine in children with ADHD [41]. In this sample, it appears that although higher acetaminophen exposure may be increasing ADHD risk through an independent mechanism, the presence of 8-hydroxy-deoxyguanosine, which could signal the baseline level of oxidative stress, may modify this risk.

Both cord methionine and cord glycine partially statistically mediated the association between acetaminophen and childhood ADHD. Unlike serine, glycine, and glutamate, methionine is an essential amino acid derived from dietary sources. In addition to being a precursor through glutathione through the transsulfuration pathway, methionine itself can also act as an antioxidant for reactive species [28,42]. Due to its role in antioxidation, methionine has been studied as a treatment for acetaminophen poisoning [43,44]. Methionine is also a precursor to the molecule S-adenosyl-methionine (SAM-e), which is an important methyl donor involved in epigenetic processes and the synthesis of monoamine neurotransmitters such as dopamine, serotonin, and norepinephrine [45]. SAM-e has been evaluated as a treatment of neuropsychiatric disorders, including ADHD, as well as in studies for acetaminophen poisoning [45-50]. While human studies are lacking, animal studies have found that excess methionine may affect fetal development, including neural development, and disturb pools of SAM-e, potentially affecting methylation of DNA and proteins [51]. Animal studies have also found that the restriction of methionine is associated with the stimulation of glutathione production and reduction of oxidative stress [28]. These studies suggest that alteration of fetal methionine levels may be involved in processes hypothesized to be implicated in neurodevelopmental disorders.

Increased levels of cord methionine could occur due to the higher maternal transfer of methionine across the placenta or due to the blockage of methionine in its downstream metabolic pathways. In this study, maternal dietary information was not available. However, maternal methionine and cord methionine levels were not found to be significantly correlated, and maternal methionine was not associated with increased risks for ADHD. This may point to increased cord methionine levels likely due to decreased fetal catabolism of methionine. It is possible that fetal metabolism of acetaminophen may affect the catabolism of methionine. Although the literature is scarce on this topic, one animal study found that the administration of acetaminophen led to a decreased expression of methionine adenosyltransferase (MAT), which is the enzyme that converts methionine to SAM-e in the transmethylation pathway, as well as depressed levels of SAM-e [52].

More research is needed to elucidate how acetaminophen may interfere with methionine metabolic pathways, particularly the transmethylation and transsulfuration pathways. A study by Thomas et al. (2008) on neonatal methionine metabolism found that after feeding, neonates had high rates of transmethylation, which may reflect high demand for cellular processes requiring methylation. Premature neonates, who have a greater risk for ADHD, had high rates of transsulfuration, which could be related to greater demands for glutathione [38,53]. Perinatal acetaminophen exposure may be disrupting these pathways early in life, potentially interfering with methylation processes and increasing the demand for glutathione, especially in premature infants.

Glycine, in addition to being involved in the synthesis of glutathione, is a known neurotransmitter that leads to excitatory neurotransmission as a co-agonist of the NMDA receptor in the brain and can have inhibitory effects at the spinal cord [54]. In rodents, high brain glycine levels have been associated with inhibition of dopamine release, which is thought to be through the co-stimulation of the NMDA receptor, and altered dopamine neurotransmission has been suggested to contribute to ADHD [55,56]. A study of children and college students found that higher glycine dietary intake was associated with ADHD diagnosis. However, the literature has also suggested that glycine supplementation may overcome NMDA dysregulation, which is thought to be involved in ADHD from animal and genetic studies, and treatments targeting the glycine site of the NMDA receptor have been proposed [57]. 
Given its role in glutathione synthesis, glycine has also been studied to overcome acetaminophen toxicity. In cell cultures of mice hepatocytes, glycine helped to prevent acetaminophen-induced necrotic cell killing [58]. In another animal study on rodents that received acetaminophen, a prodrug containing glycine prevented the depletion of glutathione and had both gastroprotective and hepatoprotective effects [59]. In the context of our study, higher cord glycine levels associated with cord acetaminophen may reflect a snapshot of when glycine was in higher demand to synthesize glutathione to overcome oxidative stress. Higher plasma glycine levels may have had an impact on neurotransmission perinatally that may contribute to ADHD development, which would explain the positive statistical mediation finding. Although cord glycine and maternal glycine were positively correlated for both ADHD and neurotypical groups, suggesting that increased glycine may be coming from the mother, maternal glycine was not associated with greater odds for ADHD. This may signal that maternal dietary glycine is not an influential factor for explaining the association between acetaminophen and ADHD, though again maternal dietary data were not available for this study.

It is important to note that a positive statistical mediation finding does not necessarily suggest a causal relationship between perinatal acetaminophen exposure and higher methionine or glycine levels. Elevated cord methionine and glycine levels may be a marker of altered catabolism due to pathways not affected by acetaminophen that are also associated with ADHD. Furthermore, this study detected partial mediation, suggesting that the association between acetaminophen exposure and ADHD mainly occurs through other direct or indirect mechanisms.

\subsection{Strengths, Limitations, and Future Directions}

To our knowledge, this is the first study that explores potential metabolic mechanisms to explain the association between perinatal acetaminophen exposure and childhood ADHD in a human sample. Major strengths include the prospective birth cohort study design and examination of multiple cord analytes involved in oxidative stress. This study offers new insight into the biological plausibility of acetaminophen toxicity on fetal neurodevelopment.

However, our study has several limitations. First, the cord plasma measurements of analytes collected at birth may reflect only a snapshot of fetal metabolism, and it is difficult to draw temporal conclusions from the correlation of the analytes. Furthermore, the relative intensities of these analytes were measured, not absolute values. Due to high rates of no detection, correlations of other cord metabolites of acetaminophen previously studied in the BBC with cord methionine could not be adequately discerned. The dataset also does not have sufficient information to correlate cord acetaminophen intensities to maternal dosage and frequency of acetaminophen use.

Second, in the main analyses presented, cord acetaminophen was modeled as a dichotomous variable with a cutoff at the 50th percentile of the sample. This was done to maximize sample size while also reflecting the graphical associations between cord acetaminophen and neurodevelopmental diagnoses. However, this may have resulted in a loss of granularity in the analyses. Third, despite adjusting for several potential cofounders, unmeasured and residual confounding may still impact the results of our analyses. For example, potential genetic confounding factors for risk of ADHD were not investigated. Acetaminophen use during late pregnancy has been associated with maternal polygenic risk scores for ADHD, which may confound the association between acetaminophen exposure and development of childhood ADHD [60]. Lastly, since this study consisted of a predominantly urban, low-income, and minority population and a preterm-enriched cohort, caution is needed to extrapolate these results to other populations.

Given the observational study design, this study should be interpreted as hypothesis generating and not causal. Our findings have implications for understanding the potential mechanism of acetaminophen toxicity on neurodevelopment and for potential shifts in guidelines for acetaminophen use during pregnancy. Driven by the growing number of 
research studies associating in utero acetaminophen exposure with adverse childhood outcomes, including neurodevelopmental outcomes, multiple researchers and doctors in a 2021 consensus statement called for the reassessment of the safety of acetaminophen use during pregnancy by U.S. and European regulators [61]. Further studies are needed to identify the potential pathways between perinatal acetaminophen exposure and fetal neurodevelopment as well as the long-term consequences of perinatal acetaminophen exposure. Future analyses could aim to directly analyze cord plasma SAM-e, dopamine, glutathione, or NAPQI levels, which were unavailable for this report, as well as other established biomarkers of oxidative stress as potential mediators of the association. Correlations of biological measurements of fetal acetaminophen levels to maternal usage of the drug are also lacking in the literature. Lastly, in this sample, we noted that children with higher cord acetaminophen levels were more likely to have low birthweight, which has been studied as a risk factor for ADHD [62-64]. Future studies could investigate low birthweight as a modifier or mediator of the perinatal acetaminophen exposure and childhood ADHD relationship.

\section{Conclusions}

In this study of the prospective Boston Birth Cohort, cord plasma amino acids involved in the synthesis of antioxidant glutathione (methionine, serine, and glycine) and the oxidative stress biomarker 8-hydroxy-deoxyguanosine were associated with increased odds of childhood ADHD. Furthermore, cord plasma methionine and glycine were statistical partial mediators of the association between higher levels of cord acetaminophen and childhood ADHD. These results suggest that oxidative stress mechanisms should be further explored to understand the link between perinatal acetaminophen exposure and risk of childhood ADHD.

Supplementary Materials: The following are available online at https:/ / www.mdpi.com/article/10 .3390 /brainsci11101302/s1, Figure S1: Association of cord plasma unmetabolized acetaminophen with childhood ADHD, Table S1: Odds of childhood ADHD stratified by cord plasma unmetabolized acetaminophen and 8-hydroxy-deoxyguanosine ${ }^{b} \leq 50$ th and $>50$ th percentile, Table S2: Adjusted logistic regressions examining risk of childhood ADHD for cord plasma metabolites stratified by sex, Table S3: Analysis of cord plasma methionine and glycine as mediators for the association between cord plasma unmetabolized acetaminophen and childhood ADHD diagnosis, Table S4: Sensitivity analyses for cord plasma methionine and glycine as a partial mediators of the association between cord plasma unmetabolized acetaminophen and childhood ADHD diagnosis, Table S5: Logistic regressions examining risk of childhood ADHD for cord plasma unmetabolized acetaminophen $>50$ th percentile and maternal plasma methionine.

Author Contributions: Data curation, X.H., C.P., B.Z. and X.W.; Formal analysis, N.S.A. and X.W.; Funding acquisition, B.Z. and X.W.; Investigation, N.S.A., B.Z. and X.W.; Methodology, N.S.A.; Project administration, X.H., C.P. and X.W.; Resources, X.H., C.P. and X.W.; Software, X.H.; Supervision, X.W.; Writing—original draft, N.S.A.; Writing—review and editing, N.S.A., R.R., G.W., R.E.A., B.Z., H.X. and X.W. All authors have read and agreed to the published version of the manuscript.

Funding: This study is supported in part by the Health Resources and Services Administration (HRSA) of the U.S. Department of Health and Human Services (HHS) under grant number UJ2MC31074, Autism Single Investigator Innovation Program. The Boston Birth Cohort (the parent study) is supported in part by the National Institutes of Health (NIH) grants (R01HD086013, 2R01HD041702, R01HD098232, R01ES031272, and R01ES031521). This information or content and conclusions are those of the authors and should not be construed as the official position or policy of, nor should any endorsements be inferred by HRSA, HHS, or the U.S. Government. The funding agencies had no involvement in the collection, analysis, or interpretation of data; in the writing of the report; or in the decision to submit the article for publication. The authors thank Linda Rosen of the Boston University Clinical Data Warehouse for assistance in obtaining relevant clinical information; the Clinical Data Warehouse service is supported by Boston University Clinical and Translational Institute and the National Institutes of Health Clinical and Translational Science Award (grant U54-TR001012). Neha S. Anand is supported by the Johns Hopkins Institute for Clinical and Translational Research (ICTR) 
which is funded in part by Grant Number TL1 TR003100 from the National Center for Advancing Translational Sciences (NCATS) a component of the National Institutes of Health (NIH), and NIH Roadmap for Medical Research. Its contents are solely the responsibility of the authors and do not necessarily represent the official view of the Johns Hopkins ICTR or UMB, NCATS or NIH.

Institutional Review Board Statement: The study was conducted according to the guidelines of the Declaration of Helsinki and approved by the Institutional Review Board of Boston University Medical Center and Johns Hopkins Bloomberg School of Public Health (IRB No. 00003966).

Informed Consent Statement: Informed consent was obtained from all subjects involved in the study.

Data Availability Statement: The data presented in this study are available on request from the corresponding author. The data are not publicly available due to participant privacy.

Acknowledgments: We thank Gayane Yenokyan (Johns Hopkins Bloomberg School of Public Health, Biostatistics Center) for consultations on analytic methods. We thank David Kossor (Clinical Center, $\mathrm{NIH}$ ) for sharing his pharmacological knowledge.

Conflicts of Interest: The authors declare no conflict of interest.

\section{References}

1. Kristensen, D.M.; Mazaud-Guittot, S.; Gaudriault, P.; Lesné, L.; Serrano, T.; Main, K.M.; Jegou, B. Analgesic use-Prevalence, biomonitoring and endocrine and reproductive effects. Nat. Rev. Endocrinol. 2016, 12, 381-393. [CrossRef]

2. Werler, M.M.; the National Birth Defects Prevention Study; Mitchell, A.; Hernandez-Diaz, S.; Honein, M.A. Use of over-the-counter medications during pregnancy. Am. J. Obstet. Gynecol. 2005, 193, 771-777. [CrossRef]

3. Brandlistuen, R.E.; Ystrom, E.; Nulman, I.; Koren, G.; Nordeng, H. Prenatal paracetamol exposure and child neurodevelopment: A sibling-controlled cohort study. Int. J. Epidemiol. 2013, 42, 1702-1713. [CrossRef]

4. Liew, Z.; Ritz, B.; Rebordosa, C.; Lee, P.-C.; Olsen, J. Acetaminophen Use During Pregnancy, Behavioral Problems, and Hyperkinetic Disorders. JAMA Pediatr. 2014, 168, 313-320. [CrossRef] [PubMed]

5. Ji, Y.; Riley, A.W.; Lee, L.-C.; Hong, X.; Wang, G.; Tsai, H.-J.; Mueller, N.T.; Pearson, C.; Thermitus, J.; Panjwani, A.; et al. Maternal Biomarkers of Acetaminophen Use and Offspring Attention Deficit Hyperactivity Disorder. Brain Sci. 2018, 8, 127. [CrossRef]

6. Ji, Y.; Azuine, R.E.; Zhang, Y.; Hou, W.; Hong, X.; Wang, G.; Riley, A.; Pearson, C.; Zuckerman, B.; Wang, X. Association of Cord Plasma Biomarkers of In Utero Acetaminophen Exposure With Risk of Attention-Deficit/Hyperactivity Disorder and Autism Spectrum Disorder in Childhood. JAMA Psychiatry 2020, 77, 180-189. [CrossRef] [PubMed]

7. Liew, Z.; Ritz, B.; Virk, J.; Olsen, J. Maternal use of acetaminophen during pregnancy and risk of autism spectrum disorders in childhood: A Danish national birth cohort study. Autism Res. 2015, 9, 951-958. [CrossRef]

8. Liew, Z.; Bach, C.C.; Asarnow, R.F.; Ritz, B.; Olsen, J. Paracetamol use during pregnancy and attention and executive function in offspring at age 5 years. Int. J. Epidemiol. 2016, 45, 2009-2017. [CrossRef]

9. Liew, Z.; Kioumourtzoglou, M.-A.; Roberts, A.L.; O’Reilly, J.; Ascherio, A.; Weisskopf, M.G. Use of Negative Control Exposure Analysis to Evaluate Confounding: An Example of Acetaminophen Exposure and Attention-Deficit/Hyperactivity Disorder in Nurses' Health Study II. Am. J. Epidemiol. 2019, 188, 768-775. [CrossRef]

10. Avella-Garcia, C.B.; Julvez, J.; Fortuny, J.; Rebordosa, C.; García-Esteban, R.; Riaño-Galan, I.; Tardon, A.; Rodríguez-Bernal, C.L.; Iñiguez, C.; Andiarena, A.; et al. Acetaminophen use in pregnancy and neurodevelopment: Attention function and autism spectrum symptoms. Int. J. Epidemiol. 2016, 45, 1987-1996. [CrossRef] [PubMed]

11. Baker, B.H.; Lugo-Candelas, C.; Wu, H.; Laue, H.E.; Boivin, A.; Gillet, V.; Aw, N.; Rahman, T.; Lepage, J.-F.; Whittingstall, K.; et al. Association of Prenatal Acetaminophen Exposure Measured in Meconium With Risk of Attention-Deficit/Hyperactivity Disorder Mediated by Frontoparietal Network Brain Connectivity. JAMA Pediatr. 2020, 174, 1073-1081. [CrossRef] [PubMed]

12. Bauer, A.Z.; Kriebel, D. Prenatal and perinatal analgesic exposure and autism: An ecological link. Environ. Health 2013, 12, 41. [CrossRef] [PubMed]

13. Chen, M.-H.; Pan, T.-L.; Wang, P.-W.; Hsu, J.-W.; Huang, K.-L.; Su, T.-P.; Li, C.-T.; Lin, W.-C.; Tsai, S.-J.; Chen, T.-J.; et al. Prenatal Exposure to Acetaminophen and the Risk of Attention-Deficit/Hyperactivity Disorder: A Nationwide Study in Taiwan. J. Clin. Psychiatry 2019, 80. [CrossRef] [PubMed]

14. Rifas-Shiman, S.L.; Cardenas, A.; Hivert, M.; Tiemeier, H.; Bertoldi, A.D.; Oken, E. Associations of prenatal or infant exposure to acetaminophen or ibuprofen with mid-childhood executive function and behaviour. Paediatr. Périnat. Epidemiol. 2019, 34, 287-298. [CrossRef] [PubMed]

15. Stergiakouli, E.; Thapar, A.; Smith, G.D. Association of Acetaminophen Use During Pregnancy With Behavioral Problems in Childhood. JAMA Pediatry 2016, 170, 964-970. [CrossRef]

16. Thompson, J.M.D.; Waldie, K.E.; Wall, C.; Murphy, R.; Mitchell, E.A. The ABC Study Group Associations between Acetaminophen Use during Pregnancy and ADHD Symptoms Measured at Ages 7 and 11 Years. PLoS ONE 2014, 9, e108210. [CrossRef] 
17. Tovo-Rodrigues, L.; Schneider, B.C.; Martins-Silva, T.; Del-Ponte, B.; De Mola, C.L.; Schuler-Faccini, L.; Vianna, F.S.L.; Munhoz, T.N.; Entiauspe, L.; Silveira, M.F.; et al. Is intrauterine exposure to acetaminophen associated with emotional and hyperactivity problems during childhood? Findings from the 2004 Pelotas birth cohort. BMC Psychiatry 2018, 18, 368. [CrossRef]

18. Ystrom, E.; Gustavson, K.; Brandlistuen, R.E.; Knudsen, G.P.; Magnus, P.; Susser, E.; Smith, G.D.; Stoltenberg, C.; Surén, P.; Håberg, S.E.; et al. Prenatal Exposure to Acetaminophen and Risk of ADHD. Pediatrics 2017, 140, e20163840. [CrossRef]

19. Gou, X.; Wang, Y.; Tang, Y.; Qu, Y.; Tang, J.; Shi, J.; Xiao, D.; Mu, D. Association of maternal prenatal acetaminophen use with the risk of attention deficit/hyperactivity disorder in offspring: A meta-analysis. Aust. N. Z. J. Psychiatry 2019, 53, 195-206. [CrossRef]

20. Kim, J.H.; Kim, J.Y.; Lee, J.; Jeong, G.H.; Lee, E.; Lee, S.; Lee, K.H.; Kronbichler, A.; Stubbs, B.; Solmi, M.; et al. Environmental risk factors, protective factors, and peripheral biomarkers for ADHD: An umbrella review. Lancet Psychiatry 2020, 7, 955-970. [CrossRef]

21. Masarwa, R.; Levine, H.; Gorelik, E.; Reif, S.; Perlman, A.; Matok, I. Prenatal Exposure to Acetaminophen and Risk for Attention Deficit Hyperactivity Disorder and Autistic Spectrum Disorder: A Systematic Review, Meta-Analysis, and Meta-Regression Analysis of Cohort Studies. Am. J. Epidemiol. 2018, 187, 1817-1827. [CrossRef]

22. Alemany, S.; Avella-García, C.; Liew, Z.; García-Esteban, R.; Inoue, K.; Cadman, T.; López-Vicente, M.; González, L.; Galán, I.R.; Andiarena, A.; et al. Prenatal and postnatal exposure to acetaminophen in relation to autism spectrum and attention-deficit and hyperactivity symptoms in childhood: Meta-analysis in six European population-based cohorts. Eur. J. Epidemiol. 2021. [CrossRef]

23. Liew, Z.; Ernst, A. Intrauterine Exposure to Acetaminophen and Adverse Developmental Outcomes: Epidemiological Findings and Methodological Issues. Curr. Environ. Health Rep. 2021, 8, 23-33. [CrossRef]

24. Bauer, A.Z.; Kriebel, D.; Herbert, M.R.; Bornehag, C.-G.; Swan, S.H. Prenatal paracetamol exposure and child neurodevelopment: A review. Horm. Behav. 2018, 101, 125-147. [CrossRef]

25. Ghanizadeh, A. Acetaminophen may mediate oxidative stress and neurotoxicity in autism. Med. Hypotheses 2012, 78, 351. [CrossRef] [PubMed]

26. Parker, W.; Hornik, C.D.; Bilbo, S.; Holzknecht, Z.E.; Gentry, L.; Rao, R.; Lin, S.S.; Herbert, M.R.; Nevison, C.D. The role of oxidative stress, inflammation and acetaminophen exposure from birth to early childhood in the induction of autism. J. Int. Med. Res. 2017, 45, 407-438. [CrossRef] [PubMed]

27. Lupattelli, A.; Spigset, O.; Twigg, M.; Zagorodnikova, K.; Mårdby, A.-C.; Moretti, M.E.; Drozd, M.; Panchaud, A.; Hameen-Anttila, K.; Rieutord, A.; et al. Medication use in pregnancy: A cross-sectional, multinational web-based study. BMJ Open 2014, 4, e004365. [CrossRef]

28. Martínez, Y.; Li, X.; Liu, G.; Bin, P.; Yan, W.; Más, D.; Valdivié, M.; Hu, C.-A.A.; Ren, W.; Yin, Y. The role of methionine on metabolism, oxidative stress, and diseases. Amino Acids 2017, 49, 2091-2098. [CrossRef] [PubMed]

29. Lu, S.C. Regulation of hepatic glutathione synthesis: Current concepts and controversies. FASEB J. 1999, 13, 1169-1183. [CrossRef]

30. Perrone, S.; Laschi, E.; Buonocore, G. Biomarkers of oxidative stress in the fetus and in the newborn. Free. Radic. Biol. Med. 2019, 142, 23-31. [CrossRef]

31. Valavanidis, A.; Vlachogianni, T.; Fiotakis, C. 8-hydroxy-2'-deoxyguanosine (8-OHdG): A Critical Biomarker of Oxidative Stress and Carcinogenesis. J. Environ. Sci. Health Part C 2009, 27, 120-139. [CrossRef] [PubMed]

32. Powell, C.L.; Kosyk, O.; Ross, P.K.; Schoonhoven, R.; Boysen, G.; Swenberg, J.A.; Heinloth, A.N.; Boorman, G.A.; Cunningham, M.L.; Paules, R.S.; et al. Phenotypic Anchoring of Acetaminophen-Induced Oxidative Stress with Gene Expression Profiles in Rat Liver. Toxicol. Sci. 2006, 93, 213-222. [CrossRef] [PubMed]

33. Raghavan, R.; Selhub, J.; Paul, L.; Ji, Y.; Wang, G.; Hong, X.; Zuckerman, B.; Fallin, M.D.; Wang, X. A prospective birth cohort study on cord blood folate subtypes and risk of autism spectrum disorder. Am. J. Clin. Nutr. 2020, 112, 1304-1317. [CrossRef]

34. Wang, X. Maternal Cigarette Smoking, Metabolic Gene Polymorphism, and Infant Birth Weight. JAMA 2002, 287, 195-202. [CrossRef] [PubMed]

35. Wang, G.; Divall, S.; Radovick, S.; Paige, D.; Ning, Y.; Chen, Z.; Ji, Y.; Hong, X.; Walker, S.O.; Caruso, D.; et al. Preterm Birth and Random Plasma Insulin Levels at Birth and in Early Childhood. JAMA 2014, 311, 587-596. [CrossRef]

36. Hong, X.; Liang, L.; Sun, Q.; Keet, C.A.; Tsai, H.-J.; Ji, Y.; Wang, G.; Ji, H.; Clish, C.; Pearson, C.; et al. Maternal triacylglycerol signature and risk of food allergy in offspring. J. Allergy Clin. Immunol. 2019, 144, 729-737. [CrossRef] [PubMed]

37. Steen, J.; Loeys, T.; Moerkerke, B.; Vansteelandt, S. Medflex: An R Package for Flexible Mediation Analysis using Natural Effect Models. J. Stat. Softw. 2017, 76, 1-46. [CrossRef]

38. Thapar, A.; Cooper, M.; Jefferies, R.; Stergiakouli, E. What causes attention deficit hyperactivity disorder? Arch. Dis. Child. 2011, 97, 260-265. [CrossRef]

39. Gustafsson, P.; Källén, K. Perinatal, maternal, and fetal characteristics of children diagnosed with attention-deficit-hyperactivity disorder: Results from a population-based study utilizing the Swedish Medical Birth Register. Dev. Med. Child Neurol. 2010, 53, 263-268. [CrossRef]

40. Verlaet, A.A.J.; Breynaert, A.; Ceulemans, B.; De Bruyne, T.; Fransen, E.; Pieters, L.; Savelkoul, H.F.J.; Hermans, N. Oxidative stress and immune aberrancies in attention-deficit/hyperactivity disorder (ADHD): A case-control comparison. Eur. Child Adolesc. Psychiatry 2018, 28, 719-729. [CrossRef]

41. Oztop, D.; Altun, H.; Baskol, G.; Ozsoy, S. Oxidative stress in children with attention deficit hyperactivity disorder. Clin. Biochem. 2012, 45, 745-748. [CrossRef] 
42. Levine, R.L.; Moskovitz, J.; Stadtman, E.R. Oxidation of Methionine in Proteins: Roles in Antioxidant Defense and Cellular Regulation. IUBMB Life 2001, 50, 301-307. [CrossRef]

43. Buckley, N.A.; Dawson, A.; Isbister, G.K. Treatments for paracetamol poisoning. BMJ 2016, 353, i2579. [CrossRef]

44. Buckley, N.; Eddleston, M. Paracetamol (acetaminophen) poisoning. BMJ Clin. Evid. 2007, 2101.

45. Gao, J.; Cahill, C.M.; Huang, X.; Roffman, J.L.; Lamon-Fava, S.; Fava, M.; Mischoulon, D.; Rogers, J.T. S-Adenosyl Methionine and Transmethylation Pathways in Neuropsychiatric Diseases Throughout Life. Neurotherapeutics 2018, 15, 156-175. [CrossRef] [PubMed]

46. Sharma, A.; as Work Group of the American Psychiatric Association Council on Research; Gerbarg, P.; Bottiglieri, T.; Massoumi, L.; Carpenter, L.L.; Lavretsky, H.; Muskin, P.R.; Brown, R.P.; Mischoulon, D. S-Adenosylmethionine (SAMe) for Neuropsychiatric Disorders. J. Clin. Psychiatry 2017, 78, e656-e667. [CrossRef] [PubMed]

47. Shekim, W.O.; Antun, F.; Hanna, G.; McCracken, J.T.; Hess, E.B. S-adenosyl-L-methionine (SAM) in adults with ADHD, RS: Preliminary results from an open trial. Psychopharmacol. Bull. 1990, 26, 249-253.

48. Green, T.; Steingart, L.; Frisch, A.; Zarchi, O.; Weizman, A.; Gothelf, R. The feasibility and safety of S-adenosyl-1-methionine (SAMe) for the treatment of neuropsychiatric symptoms in 22q11.2 deletion syndrome: A double-blind placebo-controlled trial. J. Neural Transm. 2012, 119, 1417-1423. [CrossRef]

49. Terneus, M.V.; Brown, J.M.; Carpenter, A.B.; Valentovic, M.A. Comparison of S-adenosyl-1-methionine (SAMe) and Nacetylcysteine (NAC) protective effects on hepatic damage when administered after acetaminophen overdose. Toxicology 2008, 244, 25-34. [CrossRef]

50. Brown, J.M.; Ball, J.G.; Wright, M.S.; Van Meter, S.; Valentovic, M.A. Novel protective mechanisms for S-adenosyl-1-methionine against acetaminophen hepatotoxicity: Improvement of key antioxidant enzymatic function. Toxicol. Lett. 2012, 212, 320-328. [CrossRef]

51. Rees, W.D.; Wilson, F.A.; Maloney, C. Sulfur Amino Acid Metabolism in Pregnancy: The Impact of Methionine in the Maternal Diet. J. Nutr. 2006, 136, 1701S-1705S. [CrossRef]

52. Brown, J.M.; Ball, J.G.; Hogsett, A.; Williams, T.; Valentovic, M. Temporal study of acetaminophen (APAP) and S-adenosyl-1methionine (SAMe) effects on subcellular hepatic SAMe levels and methionine adenosyltransferase (MAT) expression and activity. Toxicol. Appl. Pharmacol. 2010, 247, 1-9. [CrossRef]

53. Thomas, B.; Gruca, L.L.; Bennett, C.; Parimi, P.S.; Hanson, R.W.; Kalhan, S. Metabolism of Methionine in the Newborn Infant: Response to the Parenteral and Enteral Administration of Nutrients. Pediatr. Res. 2008, 64, 381-386. [CrossRef]

54. Hernandes, M.S.; Troncone, L.R.P. Glycine as a neurotransmitter in the forebrain: A short review. J. Neural Transm. 2009, 116, 1551-1560. [CrossRef]

55. Javitt, D.C.; Sershen, H.; Hashim, A.; Lajtha, A. Inhibition of striatal dopamine release by glycine and glycyldodecylamide. Brain Res. Bull. 2000, 52, 213-216. [CrossRef]

56. Tripp, G.; Wickens, J. Neurobiology of ADHD. Neuropharmacology 2009, 57, 579-589. [CrossRef] [PubMed]

57. Chang, J.P.-C.; Lane, H.-Y.; Tsai, G. Attention Deficit Hyperactivity Disorder and N-methyl-D-aspartate (NMDA) Dysregulation. Curr. Pharm. Des. 2014, 20, 5180-5185. [CrossRef] [PubMed]

58. Kon, K.; Ikejima, K.; Okumura, K.; Aoyama, T.; Arai, K.; Takei, Y.; Lemasters, J.J.; Sato, N. Role of apoptosis in acetaminophen hepatotoxicity. J. Gastroenterol. Hepatol. 2007, 22, S49-S52. [CrossRef]

59. Parashar, A. Pharmacological screening of glycine amino acid prodrug of acetaminophen. Indian J. Pharmacol. 2015, 47, 202-205. [CrossRef] [PubMed]

60. Leppert, B.; Havdahl, A.; Riglin, L.; Jones, H.J.; Zheng, J.; Smith, G.D.; Tilling, K.; Thapar, A.; Reichborn-Kjennerud, T.; Stergiakouli, E. Association of Maternal Neurodevelopmental Risk Alleles With Early-Life Exposures. JAMA Psychiatry 2019, 76, 834-842. [CrossRef]

61. Bauer, A.Z.; Swan, S.H.; Kriebel, D.; Liew, Z.; Taylor, H.S.; Bornehag, C.-G.; Andrade, A.M.; Olsen, J.; Jensen, R.H.; Mitchell, R.T.; et al. Paracetamol use during pregnancy-A call for precautionary action. Nat. Rev. Endocrinol. 2021. [CrossRef] [PubMed]

62. Nigg, J.T.; Song, M. ADHD and Early Experience: Revisiting the Case of Low Birth Weight. Pediatrics 2017, 141, e20173488. [CrossRef] [PubMed]

63. Momany, A.M.; Kamradt, J.M.; Nikolas, M.A. A Meta-Analysis of the Association Between Birth Weight and Attention Deficit Hyperactivity Disorder. J. Abnorm. Child Psychol. 2017, 46, 1409-1426. [CrossRef] [PubMed]

64. Pettersson, E.; Sjölander, A.; Almqvist, C.; Anckarsäter, H.; D’Onofrio, B.M.; Lichtenstein, P.; Larsson, H. Birth weight as an independent predictor of ADHD symptoms: A within-twin pair analysis. J. Child Psychol. Psychiatry 2014, 56, 453-459. [CrossRef] 